Open Access

\title{
Aberrant activation of NF-KB signaling in mammary epithelium leads to abnormal growth and ductal carcinoma in situ
}

Whitney Barham', Lianyi Chen ${ }^{1}$, Oleg Tikhomirov' ${ }^{1}$, Halina Onishko' ${ }^{1}$ Linda Gleaves², Thomas P. Stricker ${ }^{3}$, Timothy S. Blackwell ${ }^{2,4}$ and Fiona E. Yull ${ }^{1,4^{*}}$

\begin{abstract}
Background: Approximately 1 in 5 women diagnosed with breast cancer are considered to have in situ disease, most often termed ductal carcinoma in situ (DCIS). Though recognized as a risk factor for the development of more invasive cancer, it remains unclear what factors contribute to DCIS development. It has been shown that inflammation contributes to the progression of a variety of tumor types, and nuclear factor kappa B (NF-kB) is recognized as a master-regulator of inflammatory signaling. However, the contributions of NF-KB signaling to tumor initiation are less well understood. Aberrant up-regulation of NF-kB activity, either systemically or locally within the breast, could occur due to a variety of commonly experienced stimuli such as acute infection, obesity, or psychological stress. In this study, we seek to determine if activation of NF-KB in mammary epithelium could play a role in the formation of hyperplastic ductal lesions.

Methods: Our studies utilize a doxycycline-inducible transgenic mouse model in which constitutively active IKK $\beta$ is expressed specifically in mammary epithelium. All previously published models of NF-kB modulation in the virgin mammary gland have been constitutive models, with transgene or knock-out present throughout the life and development of the animal. For the first time, we will induce activation at later time points after normal ducts have formed, thus being able to determine if NF-KB activation can promote pre-malignant changes in previously normal mammary epithelium.
\end{abstract}

Results: We found that even a short pulse of NF-KB activation could induce profound remodeling of mammary ductal structures. Short-term activation created hyperproliferative, enlarged ducts with filled lumens. Increased expression of inflammatory markers was concurrent with the down-regulation of hormone receptors and markers of epithelial differentiation. Furthermore, the oncoprotein mucin 1, known to be up-regulated in human and mouse DCIS, was over-expressed and mislocalized in the activated ductal tissue.

Conclusions: These results indicate that aberrant NF-kB activation within mammary epithelium can lead to molecular and morphological changes consistent with the earliest stages of breast cancer. Thus, inhibition of NF-kB signaling following acute inflammation or the initial signs of hyperplastic ductal growth could represent an important opportunity for breast cancer prevention.

Keywords: Nuclear factor kappa-B, Mammary, Inflammation, Hyperplasia, Ductal carcinoma in situ, Mucin 1

\footnotetext{
* Correspondence: Fiona.Yull@vanderbilt.edu

'Department of Cancer Biology, Vanderbilt University Medical Center, 23rd

Ave S and Pierce PRB 325, Nashville, TN 37232, USA

${ }^{4}$ Vanderbilt-Ingram Cancer Center, 691 Preston Building, 2220 Pierce Ave,

Nashville, TN 37232, USA

Full list of author information is available at the end of the article
}

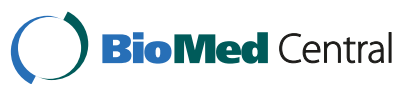

(c) 2015 Barham et al. Open Access This article is distributed under the terms of the Creative Commons Attribution 4.0 International License (http://creativecommons.org/licenses/by/4.0/), which permits unrestricted use, distribution, and reproduction in any medium, provided you give appropriate credit to the original author(s) and the source, provide a link to the Creative Commons license, and indicate if changes were made. The Creative Commons Public Domain Dedication waiver (http://creativecommons.org/publicdomain/zero/1.0/) applies to the data made available in this article, unless otherwise stated. 


\section{Background}

How cancer starts is a topic of considerable debate. In the case of breast cancer, many believe that changes in the ductal or lobular epithelium begin subtly and then progress along a continuum until they become malignant and eventually metastatic [1]. Mirroring this progression are changes in the architecture and structure of the ductal epithelium: an organized bilayer of cells begins to exhibit atypia, hyperplasia, ductal occlusion, and eventually advances to a chaotic mass [2]. This implies that finding the earliest abnormalities in ductal structure will help the clinician to intervene before the accumulated effects become life-threatening. It is based on this assumption that thousands of women are encouraged to undergo mammograms each year, and a subset to undergo tissue biopsy as a result of detection of radiographic abnormalities.

With an increased prevalence of screening, there has also been an increase in the detection of early stage lesions, many termed "ductal carcinoma in situ" (DCIS) [3]. DCIS is considered one of the earliest forms of breast cancer and is characterized by proliferating ductal epithelial cells exhibiting atypia, but not yet breaking through the basement membrane. Approximately $20 \%$ of all breast cancer diagnoses in the United States (about 60,000 cases per year) are deemed in situ [4]. The presence of these early lesions within the breast is recognized as a risk factor for invasive breast cancer occurrence, so women are treated with aggressive therapy such as lumpectomy or mastectomy sometimes followed by radiation [5]. However, the field has yet to truly understand the natural history of DCIS [6]. It remains unclear what factors contribute to its development and progression. If these factors could be determined, could we inhibit them and prevent hyperplastic lesions from occurring? In addition, are there specific signaling pathways that could be blocked to prevent them from progressing? These are critical questions, the answers to which would affect thousands of women each year.

Inflammation is recognized as a critical component for the progression of a variety of cancers [7]. Nuclear Factor Kappa-B (NF-kB) is a family of transcription factors that regulate inflammatory signaling. The most widely-studied members of this family are part of the canonical pathway, where upstream signaling induces phosphorylation of the Inhibitor of Kappa-B kinase-beta (IKK $\beta)$. This in turn phosphorylates the Inhibitor of Kappa B alpha ( $\mathrm{I} \kappa \mathrm{B} \alpha)$, targeting it for degradation. With the inhibitor gone, p65/ p50 heterodimers once held in the cytoplasm are free to enter the nucleus and affect transcription of downstream gene targets [8-11]. These include genes that participate in a wide range of cellular processes such as proliferation, apoptosis, angiogenesis, and cytokine release. It has been shown that NF-kB activity within breast tissue can increase due to stimuli such as obesity, acute infection, or physiological stress [12-14].

In a previous mammary development study, Brantley et. al found that $I_{\kappa} B \alpha$ knock out (KO) transgenic mouse epithelium develops abnormally, with hyper-branched structures and filled ductal lumens [15]. This was the first hint that there might be a link between NF- $\mathrm{kB}$ activation and the initiation of aberrant growth in breast epithelium. Though we and others have previously drawn a connection between NF- $\mathrm{kB}$ activation and mammary tumor progression, these experiments were all performed in combination with strong oncogenic or carcinogenic tumor models [16-19]. In contrast, the study noted above attempted to model the consequences of NF- $\mathrm{KB}$ activation within developing breast epithelium in the absence of any other tumorigenic stimuli.

In the current work, we use a novel doxycycline (dox) inducible transgenic mouse model to acquire deeper insights into whether activated NF- $\mathrm{kB}$ signaling in the mammary epithelium could play a role in the formation of hyperplastic breast lesions. In these transgenics, NF- $\mathrm{kB}$ is activated through expression of a constitutively active IKK $\beta$ (cIKK $\beta)$ in mammary epithelial cells [12]. Our system not only directs activation to a specific cell type (mammary epithelium), but it allows temporal control of that activation. All previously published models of NF- $\mathrm{kB}$ modulation to investigate development of the virgin mammary gland have been constitutive models, with transgene or $\mathrm{KO}$ present throughout the life and development of the animal. For the first time, we can induce activation at later time points after normal ducts have formed, thus being able to determine if $\mathrm{NF}-\mathrm{\kappa B}$ activation can promote pre-malignant changes in previously normal mammary epithelium. Through these studies, we show that NF- $\mathrm{BB}$ activation in the virgin mammary gland can lead to rapid molecular and morphological changes consistent with early mammary tumorigenesis, including hyperproliferation of ductal epithelial cells, filling of ductal lumens, macrophage infiltration, and increased expression and mislocalization of the oncogene Mucin 1 (MUC1).

\section{Methods}

\section{IKMV mouse model}

All animal experiments were approved by the Vanderbilt University Institutional Animal Care and Use Committee. Transgenic mice containing the NF- $\mathrm{kB}$ activating (tet-O)7-FLAG-cIKK2 construct [20] were mated with mouse mammary tumor virus-reverse tetracycline transactivator (MMTV-rtTA) mice [21] (gift from Dr. L. Chodosh, School of Medicine, University of Pennsylvania, Philadelphia, PA). This cross produced pups carrying both transgenes which were designated IKMV, as previously described [12]. Littermates lacking one or both transgenes 
were used as controls. All mice were on an FVB strain background. IKMV females (or littermate controls) were maintained on normal water until transgene activation was required. At the appropriate experimental time point, both IKMV and control virgin females were treated with freshly prepared doxycycline (dox) (Sigma-Aldrich), given ad libitum in drinking water $(1-2 \mathrm{~g} / \mathrm{L})$. Sucrose (5 \%) was also added to decrease the bitter taste of dox water. A red bottle was used to prevent light-induced dox degradation and water was replaced twice per week.

\section{TransAM ELISA}

Nuclear extracts from whole mammary tissue were obtained using our previously described methods [22]. Halt protease/phosphatase inhibitor cocktails (Pierce) were added to lysis buffers. Following extraction, protein concentration was assessed using a Bradford assay (BioRad). TransAM ELISA (Active Motif) was completed according to manufacturer's instructions using the anti-p65 antibody provided in the NF- $\mathrm{kB}$ family member kit (Cat \#43296). 8 micrograms of nuclear extract were added to each well, and samples were run in duplicate. A total of 4 control samples and 4 IKMV samples (6 week virgin, 3 days dox treated time point) were compared for the graph and statistics.

\section{Mammary gland transplant}

General procedures for isolation and transplantation of mammary epithelial tissue have been demonstrated previously [23]. Details of our protocol were also described in a previous manuscript [15]. With regard to the current studies, IKMV donor mammary tissue from 3-4 week old donors was transplanted into the cleared fat pad of the left inguinal mammary gland of 3 week old FVB wild type recipient females. Donor tissue taken from a littermate control was transplanted into the contralateral cleared fat pad. Tissue was collected and transplanted on the same day (no cryopreservation). After transplant, recipient mice were monitored through a 3 day recovery period during which they remained on normal water. $72 \mathrm{~h}$ post-transplant, the mice began dox treatment $(2 \mathrm{~g} / \mathrm{L})$, which was continuous until sacrifice. The mammary glands were analyzed 3 or 4 weeks after transplantation.

\section{Mammary whole mount staining}

Number 4 inguinal mammary glands of dox-treated mice were collected and spread on microscope slides at the time of sacrifice. Glands were then fixed overnight in formalin at $4{ }^{\circ} \mathrm{C}$ followed by haematoxylin staining as previously described [22]. Images were captured using a dissecting microscope and Canon Powershot A590 camera. If mice underwent transplant, the fat pad in which the transplanted tissue had been inserted was collected and placed on a microscope slide. This was then prepared and imaged in the same way as the intact IKMV and control glands.

\section{TEB size quantification}

Whole mount images were analyzed using MetaMorph software (Molecular Devices). A photo was taken of a standard ruler at the time the whole mount images were captured, using identical parameters and magnification. After images were loaded into MetaMorph, a circle was drawn around the TEB. Using the ruler photo for calibration, the software translated each region into an area measurement. The same calibration was applied to all images analyzed. 5 control and 6 IKMV transplanted glands were used for comparison of TEB size. 5 TEB's from each whole mount were measured and values averaged.

\section{Branching quantification}

Branching was quantified using Photoshop CS4 software (Adobe). Whole mounts of IKMV and control transplanted glands, treated with dox for 3 weeks, were imaged at the same session and using the same magnification. Photos were then loaded into the program and a grid of $75 \mathrm{~mm}$ squares was digitally overlaid onto each image. The number of bifurcations observed in each square was manually counted. At least 8 individual squares were counted per gland and the values averaged. 4 separate control transplanted glands and 4 IKMV transplanted glands were compared for quantification.

\section{Histology (H\&E's)}

Number 4 inguinal mammary glands (intact or transplanted fat pads) were fixed in $10 \%$ formalin overnight at $4{ }^{\circ} \mathrm{C}$. The glands were then dehydrated in a graded ethanol series followed by xylenes and embedded in paraffin. $5 \mu \mathrm{m}$ sections were prepared and stained with haematoxylin and eosin (Vanderbilt University Medical Center, Allergy, Pulmonary, and Critical Care Medicine Immunohistochemistry Core).

\section{Area of duct quantification}

To quantify the area of each duct, H\&E stained slides were used. Terminal end buds (found at the leading edge of the 6 week old glands) were excluded from all analyses. Images of ducts were captured using a Zeis Axioplain 2 microscope at 20X magnification. After capture, images were analyzed using MetaMorph software (Molecular Devices). The outer edge of each duct was traced using the drawing feature to form a polygon. The area of the polygon was then determined based on a calibration scheme (pixels to micrometers) previously performed by the Cancer Biology Microscopy Core using the 20X objective and MetaMorph software. This resulted in an area measurement for each duct in micrometers squared. If a lumen was present in the duct, 
the edges of the lumen were traced to form a second polygon. This area measurement was subtracted from the first to yield the area actually containing cells in each duct. 3 control glands and 3 IKMV glands from the each time point ( 6 week virgin or 16 week virgin) were analyzed. A minimum of 8 ducts per gland were measured.

\section{Immunohistochemistry}

PCNA staining was completed using formalin fixed, paraffin embedded tissue. Slides were deparaffinized using xylenes and a graded ethanol series and antigen retrieval was completed using citrate buffer $(\mathrm{pH} 6)$ and steam heat. After blocking with $1 \%$ BSA, slides were incubated with Biotin-conjugated PCNA monoclonal antibody (Life Technologies) at a 1:100 dilution for $1.5 \mathrm{~h}$ at room temperature. VECTASTAIN Elite ABC Kit (Mouse IgG) and VECTOR NovaRED Peroxidase (HRP) Substrate Kit were used for visualization (Vector Laboratories, Inc.), and slides were counterstained with haematoxylin. Images of 6 ducts per slide were captured using a Zeis Axioplain 2 microscope at 20X magnification. Images were then loaded into MetaMorph software (Molecular Devices) for quantification. Positive cells were manually counted and the number of positive cells normalized to the total area of each duct (area calculated as described above). Mammary glands from 3 control and 3 IKMV glands were used for quantification and 6 ducts per gland were counted. TEB's were excluded from all analyses. F4/80 staining was completed by the Vanderbilt Translational Pathology Shared Resource using a rat anti-mouse monocolonal antibody against F4/80 (CI:A3-1) (Novus Biologicals). Images were captured using a Zeis Axioplain 2 microscope at 20X magnification.

Immunofluorescent staining was completed using formalin fixed, paraffin embedded mammary tissue sections and primary antibodies against: MUC1 (AbCam); Cytokeratin-5 (Covance); Cytokeratins 8/18 (RDI-Fitzgerald); Smooth muscle actin (SMA) (CalBiochem); FLAG (Sigma); Ki-67 (Abcam); ER $\alpha$ (Thermo Fisher); and phospho-p65 (ser536) (Cell Signaling). The staining protocol was similar to above, but required blocking with $2 \% \mathrm{BSA}$ and goat serum, and addition of appropriate secondary antibodies tagged with either Alexa Fluor 488 or Alexa Fluor 594 (both Life Technologies). Slides were coverslipped using Molecular Probes ProlongGold antifade reagent (Life Technologies) to preserve fluorescence. Images were then captured using either a Zeis Axioplain 2 microscope or a LSM 510 Meta confocal microscope in the Vanderbilt University Medical Center Imaging Core. Either TO-PRO-3 (Life Technologies) or DAPI (Sigma) were used as nuclear stains.

\section{Flow cytometry}

Following sacrifice, mammary glands \#2-4 were harvested for analysis. Lymph nodes of the \#4 glands were removed prior to collection. Glands were minced and placed in $3 \mathrm{~mL}$ 's of DMEM/F12 containing $3 \mathrm{mg} / \mathrm{mL}$ of Collagenase A (Roche) and 100 units/mL Hyaluronidase (Sigma). Glands were incubated in digestion media overnight at $4{ }^{\circ} \mathrm{C}$, followed by $2 \mathrm{~h}$ of incubation at $37^{\circ} \mathrm{C}$ the following morning. After digestion, cells were pelleted and the fatty layer at the top of the supernatant was discarded. After straining cells through a 70 micron filter, red blood cells were lysed using ACK buffer. Remaining cells were then washed and counted using a hemocytometer. Cells were blocked with anti- mouse CD16/CD32 antibody (eBioscience) before staining with anti-mouse antibodies: CD45 (30-F11) (eBioscience) and F4/80 (BM8) (Life Technologies). DAPI nuclear stain was used to determine viability. Analysis was performed on an LSRII cytometer with DIVA software (BD Biosciences). Gating strategy can be found in Additional file 1. Values for the graph in Fig. 7b were obtained by taking the total number of $\mathrm{CD} 45^{+} \mathrm{F} 4 / 80^{+}$positive cells for each sample and dividing that value by the total number of viable cells in the sample (DAPI negative).

\section{RNA isolation and RT-PCR}

Mammary gland total RNA was extracted using Trizol (Invitrogen) and the RNeasy Mini Kit (Qiagen), as previously described [12]. RT-PCR was utilized to detect expression of the FLAG-tagged cIKK $\beta$ transgene (annealing temperature of $58{ }^{\circ} \mathrm{C}$ and a 35 cycle program). For all other gene targets, qRT-PCR was performed using the Applied Biosystems Stepone Plus Real-Time PCR system and SYBR Green PCR Master Mix (Applied Biosystems) (annealing temperature of $60{ }^{\circ} \mathrm{C}$ and a 40 cycle program). All primer sequences used are contained in Table 1. Each primer pair was tested and melt curves analyzed to ensure that only a single amplicon was generated. All experimental and control samples were assayed in triplicate for target gene or GAPDH (reference gene). The average of the three CT values was used as "CT" for each sample. For graphical representation, target gene $\mathrm{CT}$ values (A) and GAPDH CT values (B) were both expressed as exponents of 2 , and data represented as the ratio of $2 \mathrm{~A} / 2 \mathrm{~B}$, or $2^{(\mathrm{A}-\mathrm{B})}$. The exception is Fig. $7 \mathrm{a}$, which contains qRT-PCR data graphed as log fold change. These values were produced using the $2^{-\Delta(\Delta C T)}$ comparative method [24] and then GraphPad Prism software was used to put those values on a log scale. P values for the statistical comparison of the data in Fig. $7 \mathrm{a}$ are in Table 2.

\section{Data analysis}

Statistical analyses were performed using GraphPad Prism (GraphPad Software Inc.). In each case, paired t- 
Table $1 \mathrm{~A}$ comprehensive list of all real time primer sequences used in our studies

\begin{tabular}{|c|c|c|}
\hline Gene & Forward $\left(5^{\prime}-3^{\prime}\right)$ & $\operatorname{Rev}\left(5^{\prime}-3^{\prime}\right)$ \\
\hline GAPDH & TGAGGACCAGGTTGTCTCCT & CCCTGTTGCTGTAGCCGTAT \\
\hline CIKK2-FLAG & GGAGCTCCACCGCGGTGCGG & TCAGGGACATCTCGGGCAGC \\
\hline Cyclin bl & AAGGTGCCTGTGTGTGAACC & GTCAGCCCCATCATCTGCG \\
\hline pl8 $8^{I N 4 C}(C D K N 2 C)$ & CCTTGGGGGAACGAGTTGG & AAATTGGGATTAGCACCTCTGAG \\
\hline Muc-1 & GGCATTCGGGCTCCTITCTT & TGGAGTGGTAGTCGATGCTAAG \\
\hline CXCL1 & CCGAAGTCATAGCCACACTCAA & GCAGTCTGTCTTCTITCTCCGTTAC \\
\hline ILI- $\beta$ & GCAACTGTTCCTGAACTCAACT & ATCTITTGGGGTCCGTCAACT \\
\hline TNF-a & AGGCACTCCCCCAAAAGATG & TCACCCCGAAGTTCAGTAGACAG A \\
\hline Cox-2 & CCAGCACTTCACCCATCAGTT & ACCCAGGTCCTCGCTTATGA \\
\hline $\mathrm{CCL}-2$ & CCCACTCACCTGCTGCTACT & TCTGGACCCATTCCTTCTTG \\
\hline $\mid \mathrm{L}-12$ & GGAAGCACGGCAGCAGAATA & AACTTGAGGGAGAAGTAGGAATGG \\
\hline RANK & CCAGGAGAGGCATTATGAGCA & ACTGTCGGAGGTAGGAGTGC \\
\hline ERa & CCTCCCGCCTTCTACAGGT & CACACGGCACAGTAGCGAG \\
\hline Prolactin-R & CACTTGCTTACATGCTGCTTG & CAGGTGGTGACTGTCCATTCA \\
\hline Progesterone- $\mathrm{R}$ & GACACTGGCTGTGGAATTTCC & CCAGGATCTTGGGCAACTG \\
\hline Elf5 & ATGTTGGACTCCGTAACCCAT & GCAGGGTAGTAGTCTTCATTGCT \\
\hline Csn2 & GGCACAGGTTGTTCAGGCTT & AAGGAAGGGTGCTACTTGCTG \\
\hline
\end{tabular}

statistics with $p$-value $<0.05$ were used to determine whether the values in IKMV tissue were significantly different from those in control. Data are plotted graphically as mean vertical bars representing standard error (except for Fig. 7a). The height of the bars in Fig. 7a represent average fold change, as described above, and do not contain standard error bars.

\section{Results}

IKMV transgenic mouse model targets expression of cIKK $\beta$ specifically to mammary epithelium

Previously, our group has studied the activation of NF-kB in mammary tissue in vivo using $\mathrm{I} \kappa \mathrm{B} \alpha$ knock-out mice

Table 2 Statistical significance values for qRT-PCR shown as fold change in Fig. $7 a$

\begin{tabular}{lll}
\hline Gene & Samples Assayed (control, IKMV) & $p$ value \\
\hline CXCL1 & $n=3, n=4$ & 0.0067 \\
ILI- $\beta$ & $n=6, n=6$ & 0.0241 \\
TNF-a & $n=6, n=7$ & 0.0336 \\
Cox-2 & $n=6, n=7$ & 0.0593 \\
CCL-2 & $n=3, n=3$ & 0.0159 \\
IL-12 & $n=3, n=3$ & 0.0169 \\
RANK & $n=5, n=7$ & 0.0100 \\
ERa & $n=6, n=7$ & 0.0424 \\
Prolactin-R & $n=6, n=7$ & 0.0100 \\
Progesterone-R & $n=6, n=7$ & 0.0053 \\
Elf 5 & $n=6, n=6$ & 0.0031 \\
Csn2 & $n=4, n=4$ & 0.0038 \\
\hline
\end{tabular}

[15]. In these transgenics, deletion of the inhibitor is systemic and activity through the canonical pathway is increased within every tissue, causing mortality by day 9 post birth [25]. However, transplant of mammary tissue from 6 day old female pups into wild type donors allowed us to observe the effects of NF- $\mathrm{B}$ activation during pubertal mammary gland development. Using this model, we found an increase in lateral ductal branching and pervasive intraductal hyperplasia in the I $\mathrm{KB} \alpha$ knock-out reconstituted glands. This was the first indication that aberrant NF- $\kappa B$ activation could lead to dramatic changes in ductal growth. As in most mammary transplant methods, stromal and epithelial components were co-transplanted into recipients. Because I $\mathrm{K} \mathrm{B} \alpha$ had been deleted in both of these components, it was impossible to determine whether it was the epithelial derived NF- $\mathrm{B}$ activation that caused the resulting phenotype. To address this and to enable specific temporal regulation of the increased activation of NF-кB, we developed a doxycycline (dox) inducible model which would target activation specifically to mammary epithelium. This model requires two transgenic components: tet-O-cIKK $\beta$ mice are combined with MMTV-rtTA transgenics to produce double transgenic mice that we have termed "IKMV" (Fig. 1a). RT-PCR of whole mammary homogenates confirms the FLAG-tagged cIKK $\beta$ transgene is dox-inducible. Upon dox-treatment, transgene expression was evident in the $* *$ double transgenic IKMV mammary, but absent in dox-treated, single transgenic control mice $(-/ *)$. Double transgenic $* / *$ IKMV mice that did not receive dox-treatment showed no detectable transgene expression (Fig. 1b). Thus, in all 


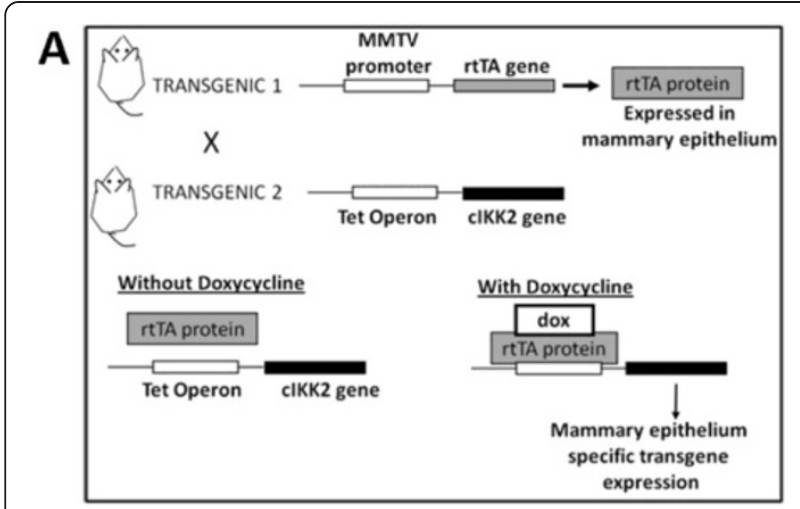

B

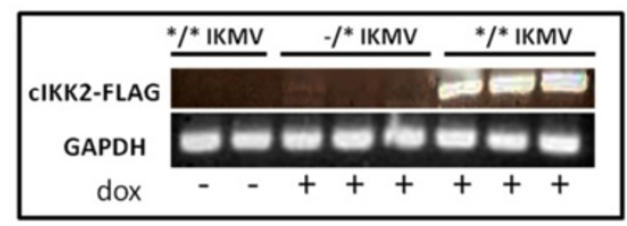

C

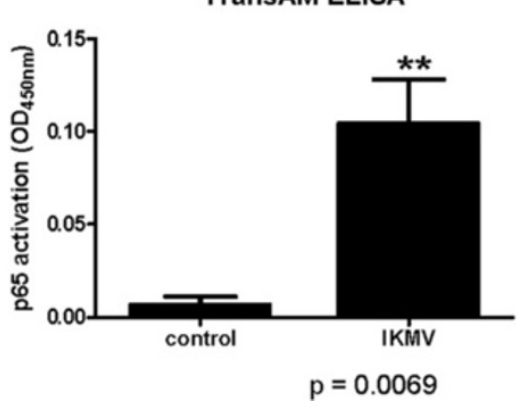

Fig. 1 Transgenic mouse model targets expression of cIKKß specifically to mammary epithelium. a Diagram shows crossing of two transgenic strains necessary to generate the double transgenic $\left(^{*} / *\right)$ IKMV mouse model with doxycycline inducible transgene expression. Littermates lacking either one or both transgenes $\left(* /-,-/^{*}\right.$, or $\left.-/-\right)$ were used throughout our studies as littermate controls. For characterization, IKMV and control littermates were treated with doxycycline ( $2 \mathrm{~g} / \mathrm{L}$ ) for 3 days and mammary tissue collected for the following assays: $\mathbf{b}$ RT-PCR of whole mammary homogenates confirms the FLAG-tagged transgene is dox-inducible. Upon dox-treatment, the transgene was expressed in the $*^{*}$ double transgenic IKMV animals, but absent in dox-treated, single transgenic control mice $\left(-{ }^{*}\right)$. Double transgenic ** IKMV mice that did not receive dox-treatment showed no detectable transgene expression. c TransAM ELISA assay using IKMV and control mammary nuclear homogenates shows that nuclear p65 in IKMV samples actively binds the NF-KB DNA consensus sequence ( $n=4$ control, $n=4$ IKMV samples; ${ }^{* *} p=0.0069$ )

subsequent studies, "IKMV" refers to the double transgenic mice and "control" refers to littermates lacking one or both transgenes, which behave as wild type mice. To confirm the ability of the transgene to activate NF- $\mathrm{kB}$ activity, TransAM ELISA was completed using the nuclear fraction of mammary tissue lysates. This showed that there is increased binding of nuclear p65 to the NF- $\mathrm{kB}$ DNA consensus sequence following transgene induction (Fig. 1c).

\section{Mammary epithelial expression of cIKK $\beta$ during ductal development results in enlarged terminal end-buds, increased lateral branching, and hyperplasia}

After validating the IKMV transgenic system, we used the mammary transplant model to produce samples that could be directly compared to our studies using the ІкB $\alpha$ KO mice. To do this, IKMV donor mammary tissue was transplanted into the cleared fat pad of 3 week old FVB wild type recipient females. Donor tissue taken from a littermate control lacking one or both transgenes was transplanted into the contralateral cleared fat pad. Recipient mice were dox-treated continuously following the transplant, and glands were analyzed at both 3 and 4 week post-transplant time points. Haematoxylin stained whole mounts of the tissue reveal that the IKMV ductal tree has on average three times the number of lateral branch points as the control transplants after 3 weeks of growth (Fig. 2). The IKMV ducts are not only hyperbranched, but also hyperplastic, as H\&E staining clearly shows filled lumens and increased cell density throughout the transgenic ducts. In addition, we found that the terminal end-buds of the IKMV glands were larger than the controls. These studies definitively show that epithelial specific NF- $\mathrm{kB}$ activation during ductal branching morphogenesis results in abnormal branching and hyperplastic ductal growth.

\section{Short term activation of NF-кB results in dramatic morphological changes within previously normal mammary ductal structure}

In our transplant studies, outgrowth of the mammary ducts and NF- $\mathrm{BB}$ activation had been simultaneous, starting when the hosts were 3 weeks of age. In order to better model early tumorigenesis without the overlay of developmental abnormalities, we induced NF- $\mathrm{kB}$ signaling after a subset of normal ductal structures had already formed. To do this, we took 6 week old virgin, intact IKMV and control females and dox-treated them for 3 days prior to collection. Surprisingly, we found that after this short pulse of transgene induction, striking changes had occurred throughout the IKMV ductal structure. The lumens of the IKMV ducts were completely filled with cells and the ducts were significantly enlarged (Fig. 3a,b). This phenotype is fully penetrant and occurs in $100 \%$ of the ducts throughout the IKMV glands. As an added control, nondox treated, double transgenic IKMV females were collected at the same 6 week old, virgin time-point. Mammary tissue from these untreated controls appeared normal, with no lumen-filling or hyperplastic ducts (Fig. 3c). 


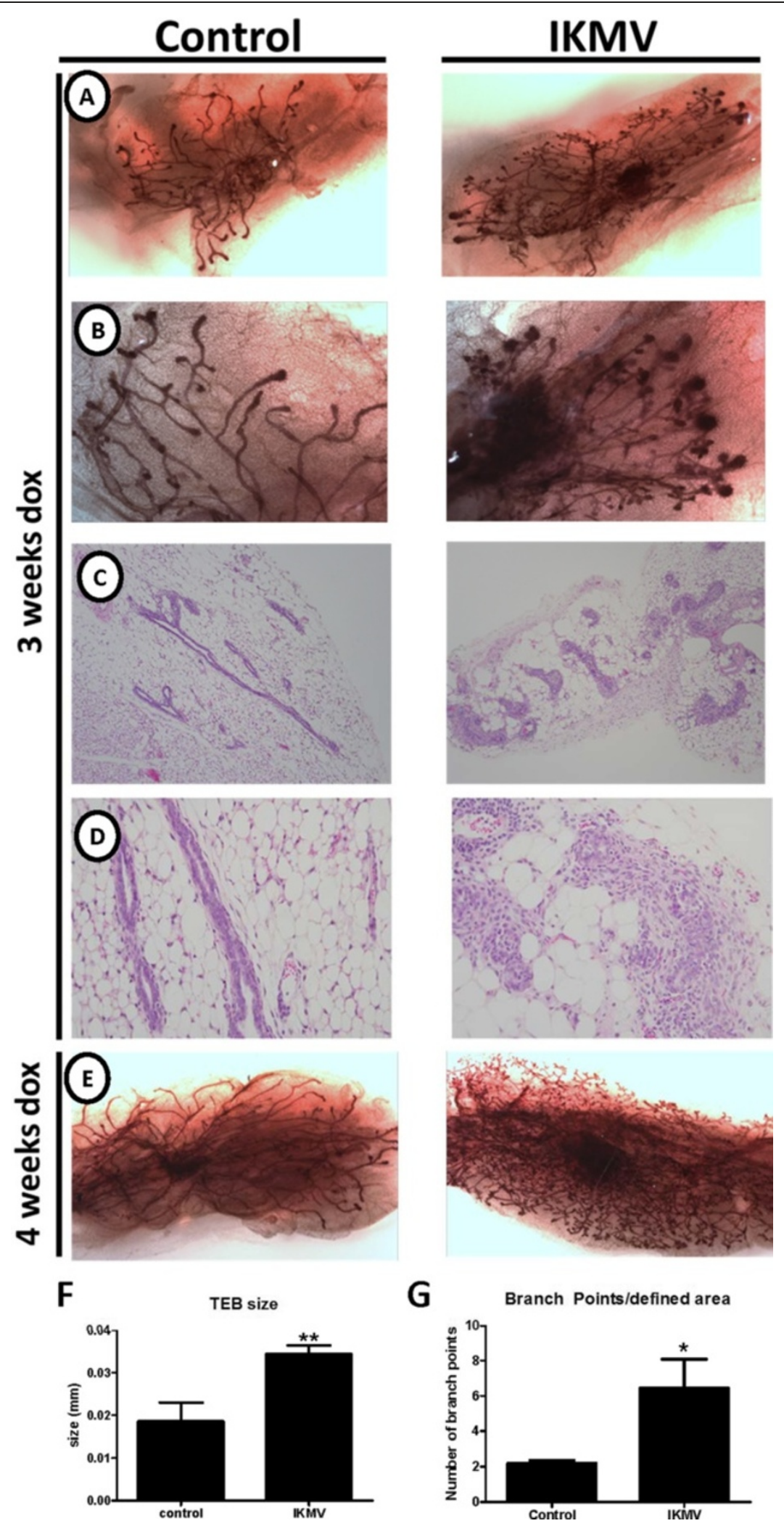

Fig. 2 (See legend on next page.) 
(See figure on previous page.)

Fig. 2 Expression of IKK 3 in transplanted mammary epithelium results in intraductal hyperplasia. Mammary tissue from 3-4 week old IKMV donors was transplanted into the cleared fat pad of the \#4 mammary gland of 3 week old FVB recipients. Tissue from control littermates was transplanted into the contralateral \#4 gland. After a $72 \mathrm{~h}$ recovery period, mice were placed on dox treatment $(2 \mathrm{~g} / \mathrm{L})$, which was continuous until sacrifice at 3 or 4 weeks post-transplant. a Haematoxylin stained whole mounts of mammary fat pads after 3 weeks of growth in recipient mice reveal increased lateral branching of IKMV tissue. b Higher magnification highlights swollen end buds in IKMV. Hyperplasia of the IKMV ducts is evident in images of H\&E stained tissue using c 10X and $\mathbf{d} 20 \mathrm{X}$ objectives. e Whole mounts of mammary tissue after 4 weeks of growth indicate that IKMV tissue continues to fill fat pad with hyperplastic tissue. The observed phenotype was quantitatively assessed through: $\mathbf{f}$ quantification of terminal end bud (TEB) size $\left(n=5\right.$ control, $n=6$ IKMV glands, $\left.{ }^{*} p=0.0071\right)$ g quantification of the number of lateral branch points per field ( $n=4$ control, $n=4$ IKMV glands, ${ }^{*} p=0.0416$ )

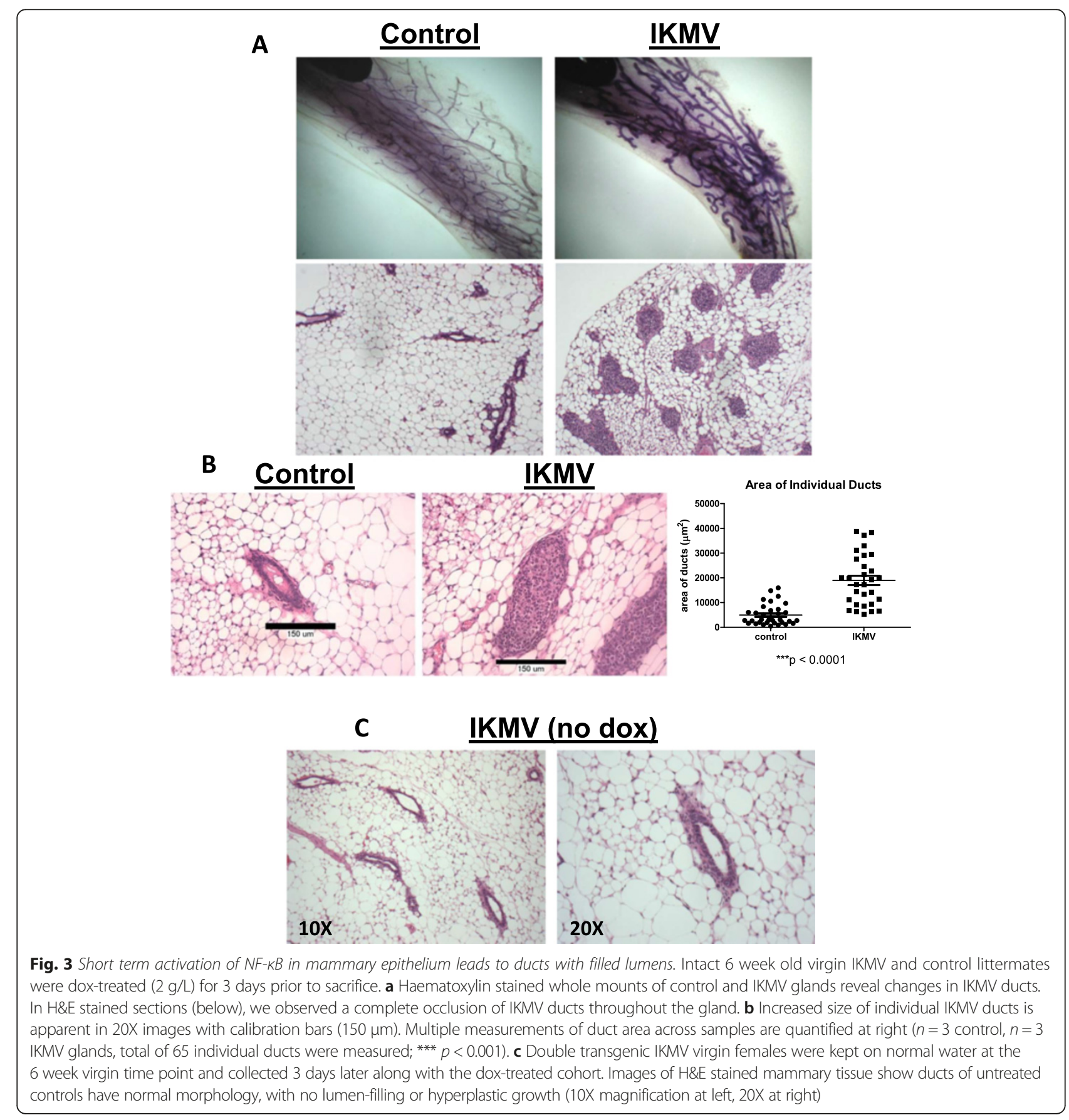


This confirmed that the phenotype in the dox-treated IKMV mice occurred within the 3 day induction window.

Upon observing such a dramatic filling of the IKMV ducts, we endeavored to determine whether the cells within the ducts were epithelial. To do this, we completed immunofluorescent staining for the luminal epithelial marker cytokeratin 8/18 (CK8/18). This revealed that many of the cells filling the lumens stain positive for this marker (Fig. 4a). In addition, FLAGtagged transgene expression was found throughout the aberrant ducts in IKMV glands (Fig. 4b). Since transgene expression is specific to MMTV-rtTA expressing mammary epithelial cells in the IKMV system, this again suggests that many of the cells filling the ducts are epithelial. Finally, we wanted to confirm that the transgene expression was indeed driving NF- $\mathrm{kB}$ activation within the epithelium at the 3 day time point. Using immunofluorescent staining, and high magnification images, we observed cytoplasmic localization of the transgene within mammary epithelial cells resulting in robust nuclear localization of phospho-p65 (ser 536) (Fig. 4b).

As 6 week old virgin mice are still undergoing puberty, the mammary tissue may be responding to a higher level of hormonal stimulation than quiescent, adult glands. To determine if the phenotype would also occur in adult mice, we treated 16 week old virgin IKMV and control females with dox for 10 days. Upon collection, we saw that the IKMV ducts were significantly larger than the control ducts in cross sectional area and had indeed become filled with cells (Fig. 5). This indicated that the notable changes in the IKMV ductal structure after a short-term induction of NF-kB activity were not dependent on puberty-related physiological factors.

\section{Cells filling the abnormal ducts are highly proliferative}

Lumen-filling can be the result of decreased apoptosis and/or increased proliferation and NF- $\mathrm{kB}$ signaling plays a role in both of these cellular processes [26]. To determine
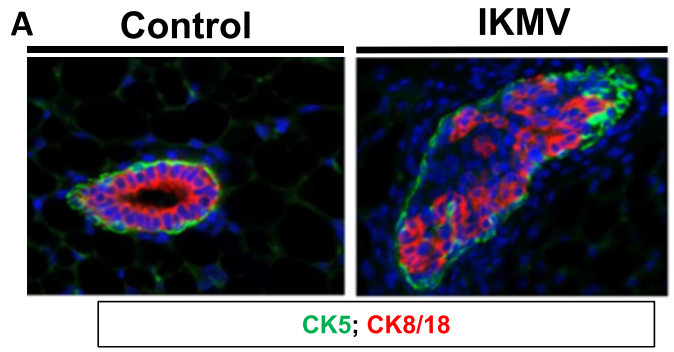

B
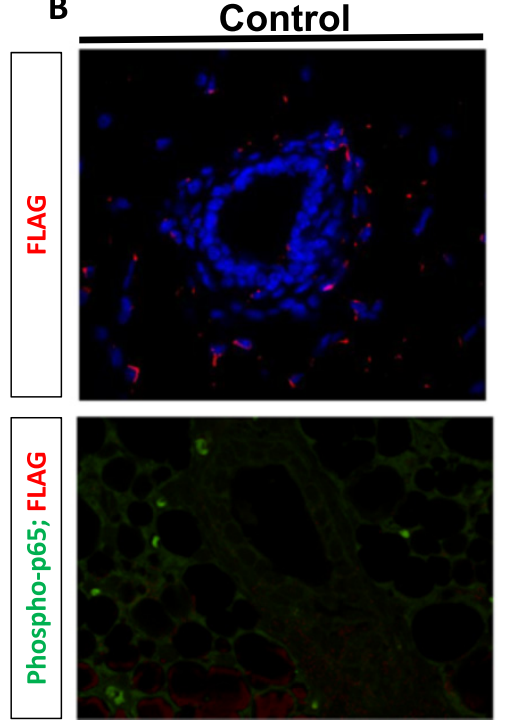
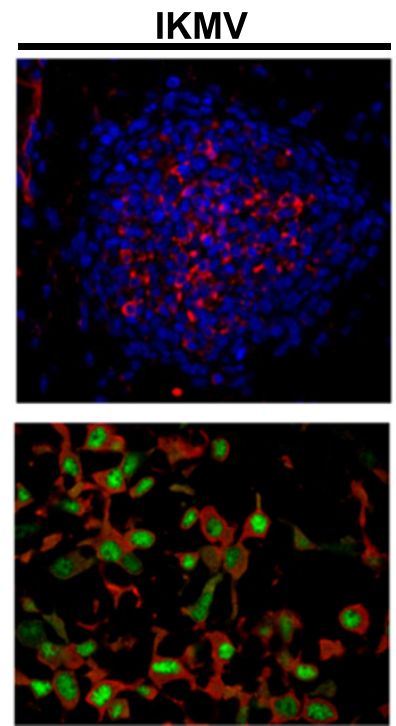

Fig. 4 Many cells within aberrant ducts are epithelial, transgene-expressing, and have high levels of NF-KB activation. 6 week old virgin IKMV and control littermates were dox-treated $(2 \mathrm{~g} / \mathrm{L}$ ) for 3 days prior to sacrifice. a Immunofluorescent staining of control and IKMV tissue reveals that IKMV ducts are filled with CK8/18 positive luminal epithelium. CK5 and SMA were used as markers of basal/myoepithelium. b Separate staining shows that the FLAG-tagged CIKK 3 transgene is expressed by cells within the IKMV hyperplastic ducts (red, FLAG stain). In addition, high magnification images of ductal tissue from IKMV and control littermates confirmed that the transgene is localized appropriately within the cytoplasm of IKMV mammary epithelium and is driving concurrent nuclear localization of phospho-p65 (green) 


\section{Control}

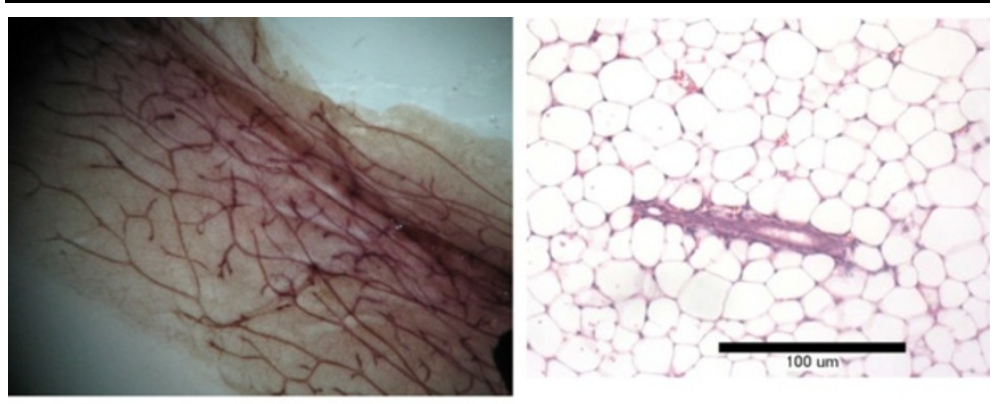

IKMV

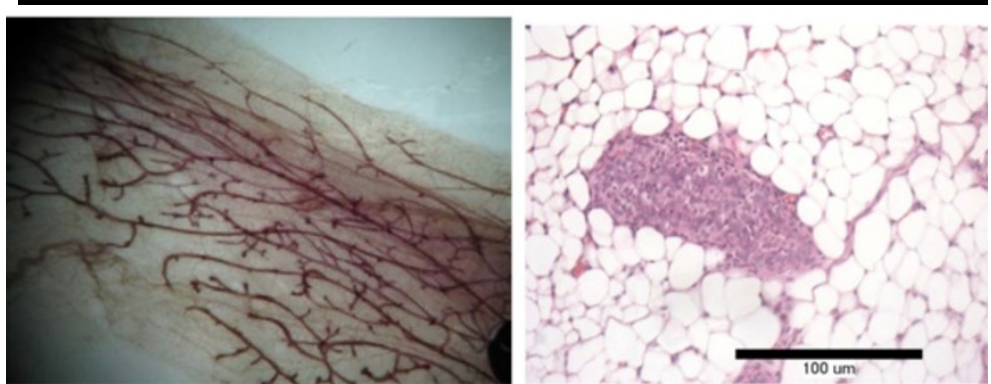

Area of Individual Ducts

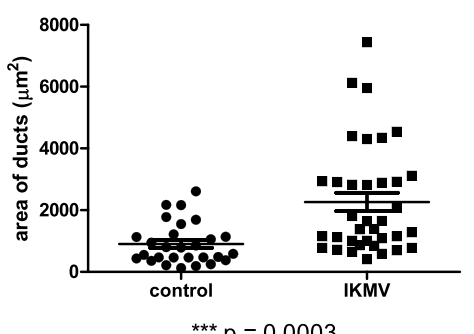

${ }^{* * *} p=0.0003$

Fig. 5 Abnormal ducts induced in fully adult, virgin glands through activation of NF-KB in mammary epithelium. 16 week old adult, virgin IKMV and control females, which were previously untreated, were given dox (1 g/L) for 10 days prior to sacrifice. A subtle enlargement of ducts can be seen in haematoxylin stained whole mounts (left panels). The phenotype is more apparent in H\&E stained sections (100 $\mu$ m calibration bar) (right panels). IKMV ducts are filled with cells and significantly larger than the controls. Size of ducts is quantified below images ( $n=3$ control and $n=3$ IKMV glands, total of 64 ducts were measured; ${ }^{* * *} p=0.0003$ )

the mechanism most relevant to the rapid filling of the IKMV ducts, we assessed the mammary tissue from 3 day dox treated IKMV and control mice to detect changes in apoptosis or proliferation. To quantify apoptotic cells, we stained the tissue with caspase- 3 , but found no significant change in the number of caspase- 3 positive cells in IKMV vs. control tissue (data not shown). To assess proliferation in the glands, we stained for proliferating cell nuclear antigen (PCNA) (Fig. 6a-c). This revealed a profound increase in the number of proliferating cells within the IKMV ducts. All of the enlarged ductal structures contained PCNA positive cells, indicating that proliferation is the principle mechanism by which the ducts become filled with epithelium in such a short span of time.
Next, we looked for molecular markers of increased epithelial proliferation present in the IKMV glands. Cyclin b1is known to induce cellular transition from $G 2$ to $M$ phase and is often overexpressed in human breast malignancies [27]. Quantitative PCR (qRT-PCR) revealed increased mRNA expression of cyclin b1 in IKMV mammary tissue (Fig. 6d). Furthermore, expression of the mitotic inhibitor $\mathrm{p} 18^{\mathrm{INK} 4 \mathrm{c}}$ (CDKN2C) was significantly decreased in IKMV tissue (Fig. 6e). This change is consistent with the observed phenotype, as $\mathrm{p} 18^{\mathrm{INK} 4 \mathrm{c}}$ normally functions to restrain luminal progenitor cell expansion and inhibit luminal tumorigenesis in the mammary gland [28].

To further confirm that it was truly epithelial cells undergoing proliferation within the IKMV ducts, we co-stained 


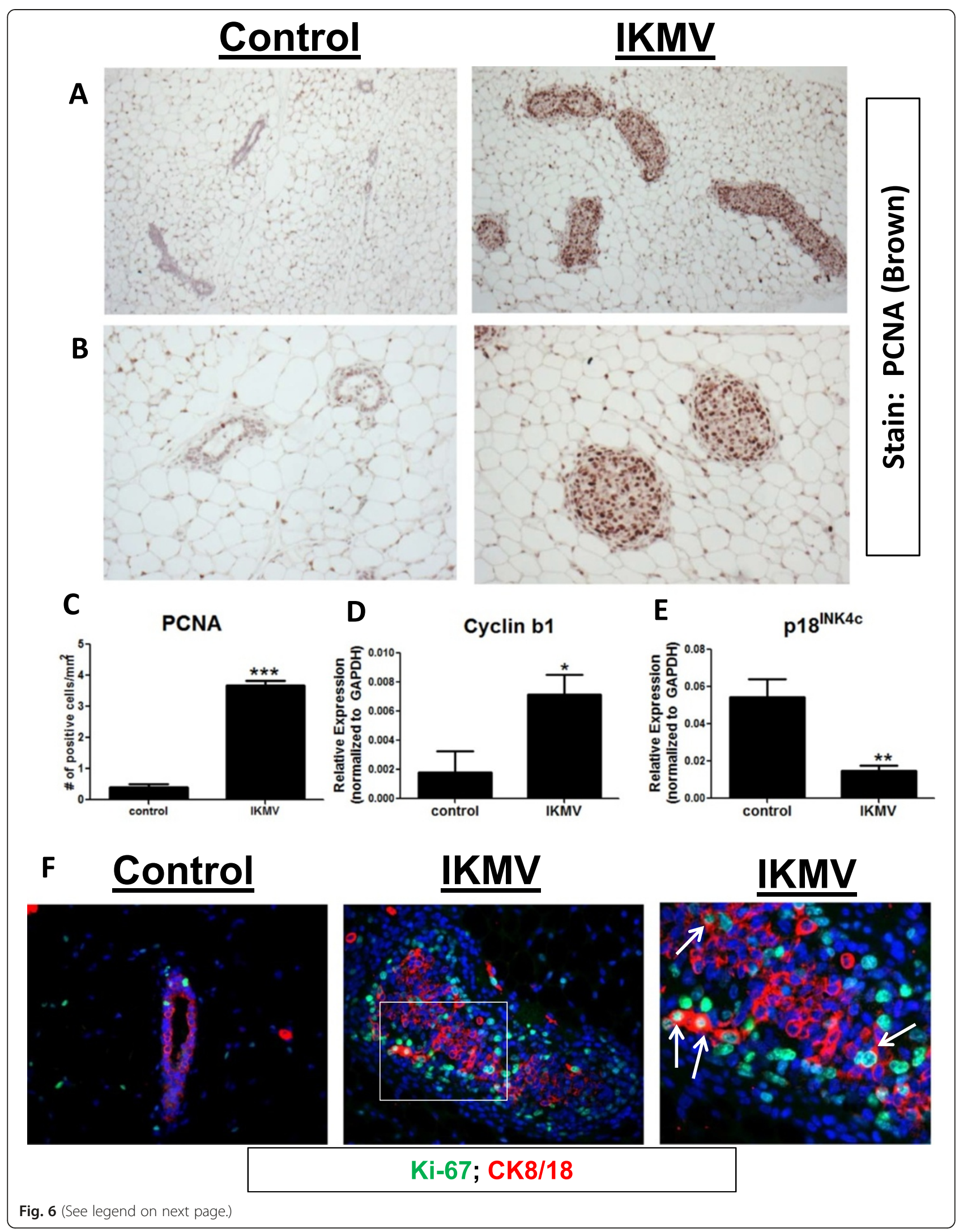


(See figure on previous page.)

Fig. 6 Cells filling abnormal IKMV ducts are highly proliferative. 6 week old virgin IKMV and control littermates were dox-treated (2 g/L) for 3 days prior to sacrifice. PCNA staining of mammary tissue reveals increased proliferation in the IKMV ducts as compared to controls, shown in both a $10 \mathrm{X}$ and b 20X images (positive staining is dark brown). c This increased number of PCNA positive cells/duct was quantified (counts were normalized to area of each duct; $n=3$ control, $n=3$ IKMV glands were used for quantification and 6 ducts per gland were counted; $\left.{ }^{* * *} p<0.0001\right)$. d,e qRT-PCR analysis shows increased expression of cyclin b1 and decreased expression of p18 ${ }^{\mathrm{INK} 4 \mathrm{c}}$ following activation of NF-KB in mammary epithelium ( $n=6$ control, $n=7$ IKMV samples run for cyclin b1; ${ }^{*} p=0.0210 ; n=3$ control, $n=4 \mathrm{IKMV}$ samples run for $p 18^{\mathrm{IKN} 4 \mathrm{c}} ;{ }^{*} p=0.0064$ ). f Immunofluorescent staining for Ki-67 (green, nuclear) confirms that cells within the IKMV ducts are actively cycling. Many of the proliferating cells co-stain with CK8/18 (red, cytoplasmic), indicating that the luminal epithelium is driven to proliferate upon activation of NF-KB. Note that the far right image is a magnification of the white box in the center image. White arrows indicate double positive Ki-67/CK8/18 cells

control and IKMV mammary tissue (collected after 3 days of dox treatment) with the proliferative marker Ki-67 and the luminal epithelial marker CK8/18 (Fig. 6f). Ki-67 staining confirmed our earlier findings using the PCNA stain, as nuclear Ki-67 was observed in cells throughout the IKMV ducts. A number of these proliferating cells were also positive for CK8/18 (double positive cells indicated by arrows, Fig. 6f).

\section{Increased expression of inflammatory markers in IKMV mammary is concurrent with the down-regulation of hormone receptors and markers of epithelial differentiation}

Our results show that activation of NF- $\mathrm{kB}$ in mammary epithelium results in a rapid proliferative response and induces a hyperplastic ductal structure. Because NF- $k B$ signaling can drive downstream expression (and sometimes repression) of hundreds of gene targets, we wondered what other molecular changes were occurring after NF-kB activation in the mammary ducts and how they could be mediating the observed phenotype. To achieve this, we completed a panel of qRT-PCR assays (Fig. 7a). Our analysis revealed that downstream read-outs of inflammatory signaling, such as CXCL1, IL-1 $\beta$, TNF- $\alpha$, and Cox-2, were significantly increased in the IKMV tissue. Interestingly, increased expression of many of these products (IL- $1 \beta, \mathrm{TNF} \alpha$, and Cox-2) has been implicated in previous studies to contribute to mammary hyperplasia and tumorigenesis [2931]. In addition, our analysis revealed a small but significant increase in the expression of Receptor Activator of NF-kB Kinase (RANK) in the IKMV mammary gland. Previous studies have shown that increased signaling through RANK/RANK-L in the mammary gland can lead to expansion of the epithelium, disruptions in differentiation, and disorganization of the basal/luminal structure. Also upregulated were genes associated with an influx of inflammatory cells, specifically macrophages. CCL2 is a macrophage chemoattractant, and its expression was increased in the activated tissue. Accordingly, we found an increased percentage of F4/80 positive cells within the IKMV mammary tissue via flow cytometry analysis (Fig. 7b). Immunohistochemistry for F4/80 revealed that in control samples, macrophages are sparse and localized along the outer edge of the ducts, as expected. In the IKMV tissue, the F4/80 positive cells appear both around the outer edge and on the inside of the ducts, interspersed between the hyperplastic epithelium (Fig. 7c). We also detected an increased level of IL-12 transcript in the IKMV tissue, indicating that the recruited macrophages are likely more aligned with a classically activated phenotype.

Converse to the up-regulation of these inflammatory components, we observed decreased hormone receptor expression in the IKMV mammary, including lower levels of estrogen receptor alpha $(E R \alpha)$, progesterone receptor, and prolactin receptor. Immunofluorescent staining reveals decreased nuclear localization of ER $\alpha$ in IKMV ducts (Fig. 7d). These decreases suggest that the proliferative response cannot be explained by increases in hormonal signaling. We also observed a striking decrease in the expression of $\beta$-casein (Csn2), a marker of mammary epithelial differentiation. In addition, expression of Elf-5, a key regulator of mammary epithelial differentiation, was also decreased in IKMV epithelium. Deletion of Elf-5 can lead to disorganized mammary structures and collapsed lumens, suggesting that this decrease in expression could be playing a role in the observed phenotype [32].

\section{Pathological review of IKMV tissue confirms diagnosis of low-grade DCIS}

To determine the staging of the IKMV ductal abnormalities, the H\&E stained sections were analyzed by Dr. Thomas Stricker MD/PhD, pathologist at Vanderbilt University Medical Center. Dr. Striker observed that the ducts in the IKMV mice were expanded, containing mildly atypical cells with increased nuclear-cytoplasmic ratio, chromatin condensation, nuclear membrane abnormalities, and nucleoli. Furthermore, he found that cells in the glands were well spaced out with few overlapping nuclei and that there were increased numbers of apoptotic cells. Taken together, he concluded that these findings are consistent with a diagnosis of low-grade DCIS.

\section{MUC1 oncoprotein is up-regulated and mislocalized in IKMV mammary epithelium}

To further strengthen correlations between the IKMV phenotype and DCIS, we analyzed the expression and localization of Mucin 1 (MUC1). This protein is normally expressed on the apical surface of mammary epithelium 

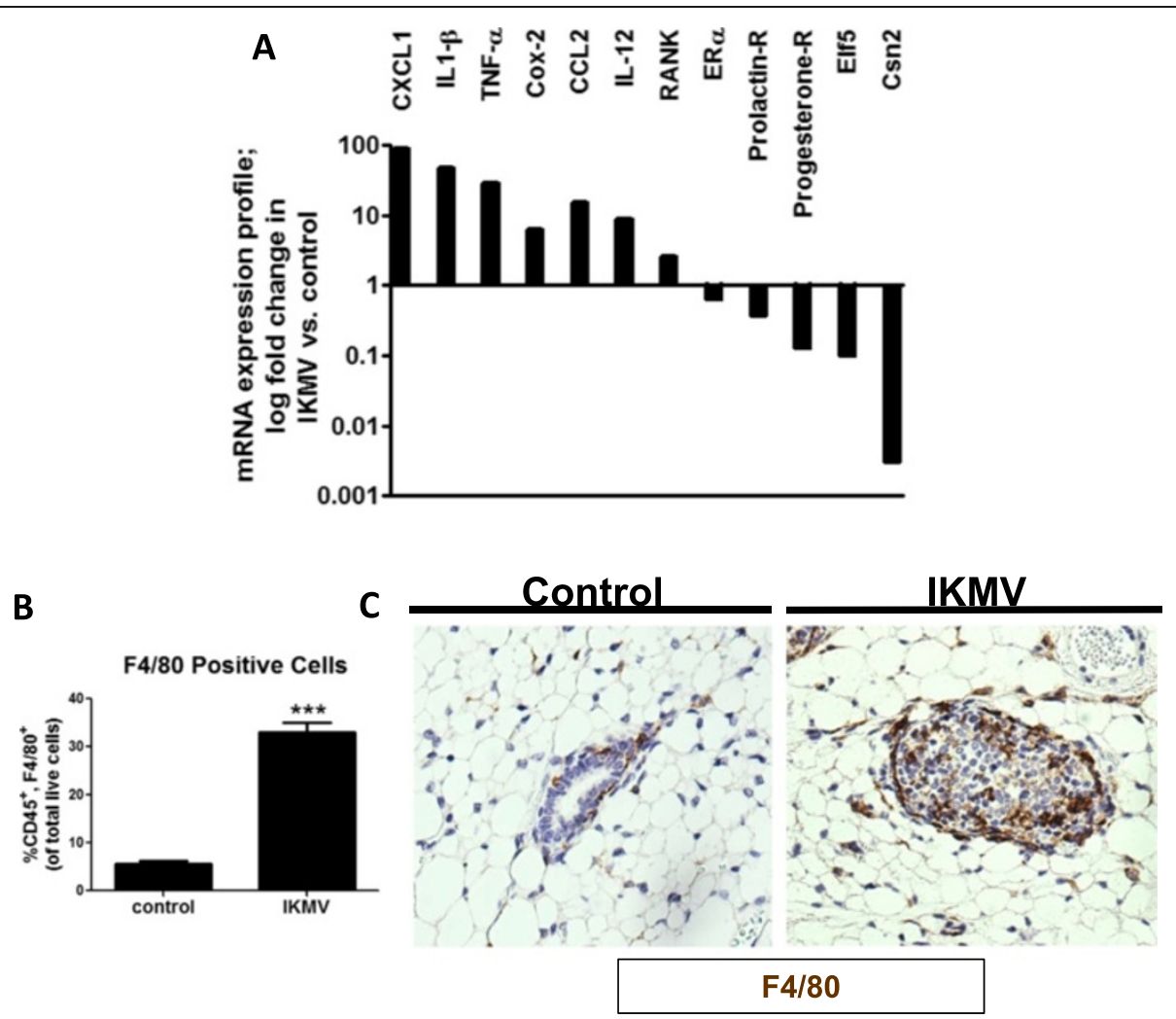

D

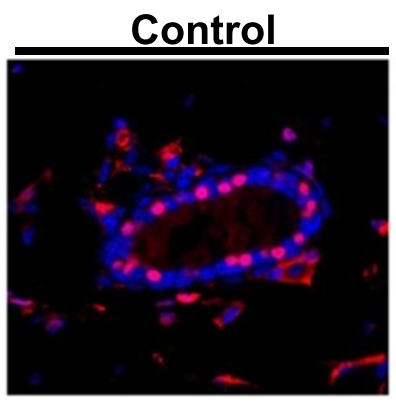

IKMV

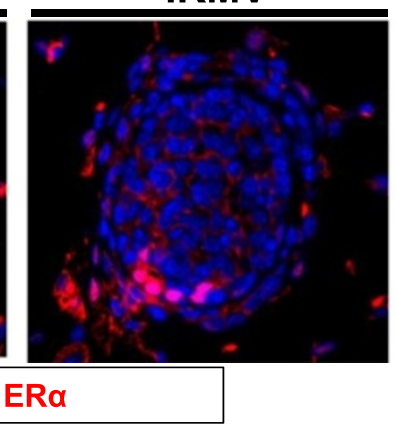

Fig. 7 Aberrant activation of NF-KB in mammary epithelium induces downstream signaling consistent with early tumorigenesis. RNA was isolated from mammary glands of IKMV and control mice after 3 days of dox treatment ( 6 week time point). a qRT-PCR for a variety of gene targets revealed increased expression of inflammatory markers as well as decreased expression of hormone receptors and markers of epithelial differentiation (bars represent log fold change of IKMV vs. control; $p$ values for each comparison can be found in Table 2. b Flow cytometry indicates there is an increased percentage of $\mathrm{CD} 45^{+} / \mathrm{F} 4 / 80^{+}$macrophages in mammary glands following NF-KB activation, and $\mathbf{c}$ immunohistochemistry reveals that F4/80 positive macrophages have infiltrated the mammary ducts of IKMV mice (positive cells are dark brown). $\mathbf{d}$ Immunofluorescent staining reveals decreased nuclear localization of ERa in IKMV ducts (red; dense and nuclear in control epithelium)

where, similar to other mucins, it plays a role in host defense against pathogens. Beyond this role in normal physiology, MUC1 is considered an oncoprotein, as its overexpression can functionally drive malignant transformation in breast epithelium [33]. When luminal epithelial cells lose their polarity due to stress or transformation, MUC1 can be expressed around the entire cell membrane rather than staying localized to the apical surface. This repositioning of MUC1 has been noted in both ductal hyperplasia with atypia and in DCIS of the breast [34]. We analyzed our 6 week virgin, 3 day dox treated samples for MUC1 expression and observed a significant up-regulation of MUC1 in IKMV tissue via qRT-PCR (Fig. 8a). Further, we completed immunofluorescent staining and found that IKMV ducts contained MUC1 positive cells dispersed throughout the filled lumens (Fig. 8b). These positive cells displayed MUC1 staining around the entire cell membrane. This was in contrast to the control ducts, which had 

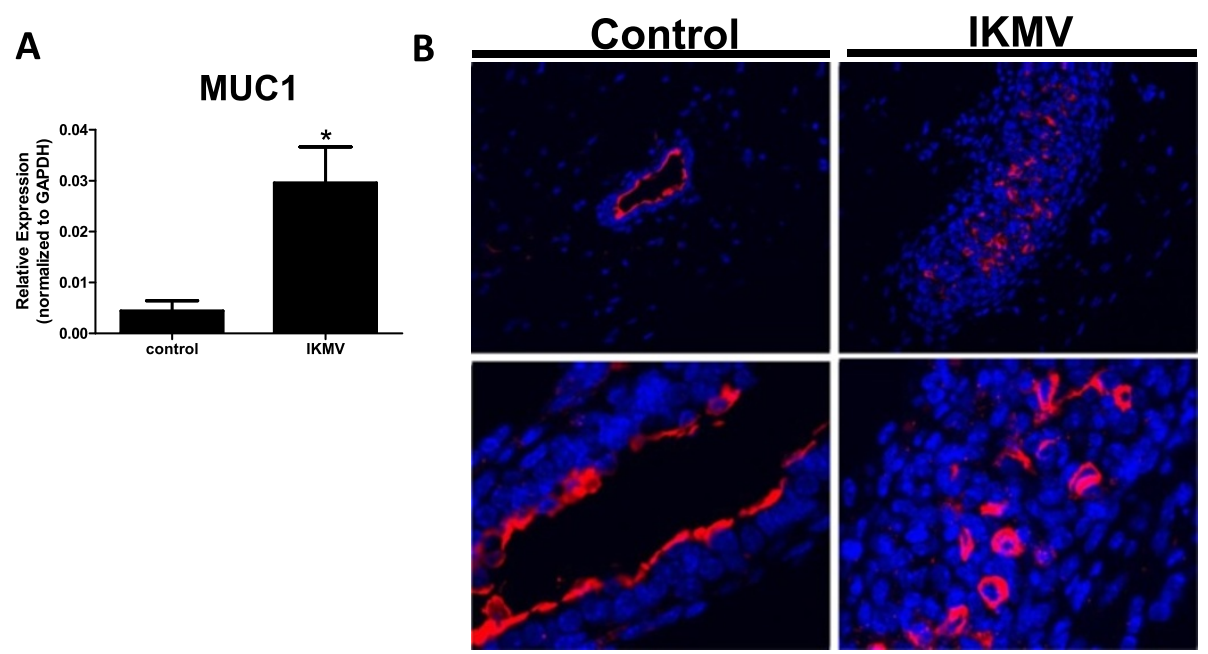

MUC1

Fig. $8 \mathrm{MUC1}$ oncoprotein is up-regulated and mislocalized in IKMV mammary epithelium. RNA was isolated from mammary glands of IKMV and control mice after 3 days of dox treatment ( 6 week time point). a The hyperplastic IKMV ducts have increased expression of MUC1 via qRT-PCR ( $n=5$ control, $n=6$ IKMV samples; ${ }^{*} p=0.0119$ ). $\mathbf{b}$ Staining for MUC1 indicates that it is properly localized to the apical surface of luminal epithelium in control ducts but it has become repositioned to the entire cell membrane in many of the cells within the IKMV hyperplastic ducts (red staining is MUC1, blue is DAPI; 40X images are shown; images at bottom are magnified to show detail)

appropriately localized MUC1 along the apical surface of each lumen.

\section{Discussion}

In this study, we have modeled specific activation of NF$\kappa \mathrm{B}$ signaling in virgin mammary epithelium and demonstrated a variety of downstream morphological and molecular consequences.

Transplant studies using IKMV transgenic tissue revealed that aberrant activation of NF- $\mathrm{kB}$ during ductal outgrowth leads to hyper-branched, hyperplastic ductal structures. The resulting phenotype is strikingly similar to the studies completed using I $\mathrm{I} \mathrm{B} \alpha \mathrm{KO}$ tissue even though the current model uses a different means of pathway intervention (constitutive IKK $\beta$ ). In addition, further analyses in both models indicated that the expanded epithelium in activated tissue was the result of increased proliferation, not decreased apoptosis. Because the IKMV transgene is epithelial specific, we definitively show that aberrant NF-kB signaling originating within the epithelium can drive these morphological changes. It has been suggested that hyperplastic growth of ductal tissue is the result of stromal changes and that the epithelium is influenced to become malignant because its environment has provided a permissive niche [35]. In future studies, it would be intriguing to determine if the observed alterations in epithelial signaling and structure could be induced by starting the cross-talk from the other direction and initiating NF- $\mathrm{kB}$ activation specifically in the stroma. One published study suggests this may be the case: when AEBP1, an inflammatory mediator, was overexpressed in macrophages and adipocytes, it was able to activate NF- $\mathrm{kB}$ activity in the mammary gland and led to alveolar hyperplasia [36].

After completing the transplant studies, we hypothesized that NF-kB-driven hyperplastic growth might play a role in the formation of hyperplastic breast lesions, or DCIS. This could now be formally tested using the temporal control provided in the IKMV model. We found that we could establish a network of normal ducts in 6 week old virgin females, and then induce hyperplasia through 3 days of aberrant NF- $\mathrm{kB}$ signaling. In addition, similar changes occurred upon activation of the epithelium in a fully adult, 16 week old gland. One striking aspect of this phenotype is its rapid induction. Though aberrant signaling through other cell-signaling pathways is certainly able to induce mammary ductal hyperplasia, it is often over a period of weeks or months, not days. A noted exception is activation of FGF-receptor 1 (FGFR-1) in mammary epithelium. Welm et al. induced FGFR-1 transgene activation at the 6 week virgin time point and observed rapid formation of hyperplastic ductal structures accompanied by increased inflammatory signaling and macrophage recruitment [37]. It was later shown that IL1- $\beta$ secretion by the recruited macrophages was playing a significant role in the hyperplastic growth, as blocking IL1- $\beta$ or depleting macrophages abrogated the effects of FGFR-1 signaling [29]. They note that IL1- $\beta$ treatment of mammary epithelial cells induces NF- $\mathrm{kB}$ activation, which suggests that the phenotype we observe in the IKMV model could be mediated, at least in 
part, by paracrine IL1- $\beta$ secretion. While the timing is similar, hyperplastic growth in the FGFR-1 model is the result of increased lateral budding of the epithelium, whereas the IKMV model exhibits lumen-filling and duct enlargement. Thus, there are likely somewhat different mechanisms at play in the two systems.

Another striking feature of the IKMV short-term model is the robust proliferative response induced after NF- $\mathrm{kB}$ activation. Mechanistically, this could be mediated by direct binding of NF- $\mathrm{kB}$ to the promoter of cell-cycle mediators, as it has been shown to transcriptionally regulate cyclin d1[38]. However, we did not find a significant increase in cyclin d1 mRNA expression in IKMV vs. control glands after the three day dox treatment (data not shown). We did observe changes in two other cell cycle mediators: cyclin b1 and p18 ${ }^{\mathrm{INK} 4 \mathrm{c}}$. As noted earlier, both an increase in cyclin b1 and a decrease in $\mathrm{p} 18^{\mathrm{INK} 4 \mathrm{c}}$ have been associated with pro-tumorigenic changes in the breast. No study has noted the presence of an NF-kB consensus binding site in either of these genes' promoters. Nevertheless, some reports indicate that p65 (and other family members) can bind to numerous sites other than the recognized consensus sequence, such as Alu-repetitive elements in DNA. Via CHIP analysis, it was shown that NF-kB bound the p18 ${ }^{\mathrm{INK} 4 \mathrm{c}}$ promoter, which contains these Alu-repeats, following viral infection of Hela cells [39]. Continued studies of how NF- $\mathrm{B}$ can directly regulate expression of numerous cell cycle related genes is warranted, given these findings. In addition, proliferation in the IKMV ducts could be induced through an indirect mechanism, mediated by NF$\kappa B$-driven production of pro-inflammatory factors. Increased expression of both TNF- $\alpha$ and Cox- 2 was apparent in the IKMV tissue. TNF- $\alpha$ has been shown to promote anchorage independent growth and invasion in mammary epithelial cells, and overexpression of Cox-2 in mammary epithelium is sufficient to induce hyperplastic growth of virgin ducts [30, 31]. Likely, a combination of both direct and indirect mechanisms leads to proliferation and hyperplastic growth in the IKMV ducts.

We determined that aberrant NF- $\mathrm{B}$ activation leads to decreased expression of hormone receptors and other markers of mammary epithelial differentiation such as Elf5 and CSN2. This is consistent with our previous report of a dramatic decrease in CSN2 mRNA expression and protein levels upon NF- $\mathrm{KB}$ activation in lactating mammary glands [12]. It was also previously shown that constitutive activation of RANK in the mammary epithelium can lead to decreased ELF5 expression [40]. These observed decreases in markers of epithelial differentiation following NF- $\mathrm{kB}$ activation are consistent with reports that NF- $\mathrm{kB}$ can function to reprogram mammary epithelium, leading to epithelial to mesenchymal transition (EMT) [41]. We did not detect significant mRNA changes in classic indicators of EMT such as Vimentin,
Zo-1, E-cadherin, or N-cadherin, in the IKMV tissue (data not shown), but it is possible that these types of changes may be more apparent at other time points.

We observed two additional clinical markers of tumorigenesis within the hyperplastic IKMV ducts: infiltration of macrophages and the up-regulation and mislocalization of MUC1. Macrophage infiltration and CCL2 expression are correlated with poor prognosis and metastasis in human breast cancer $[42,43]$. It has been shown that NF-kB activation in the mammary epithelium enhances macrophage recruitment to the site of primary mammary tumors in both the polyoma middle $\mathrm{T}$ and Erb2 oncogene-driven mouse mammary tumor models $[16,18]$. In the current study, we find that NF- $\mathrm{BB}$ activation, in the absence of any oncogenic mutation, results in significant macrophage infiltration into the ducts. These immune cells are likely acting in an "M1" role initially, responding to the inflammatory signals as they would to an infection. It will be interesting in future studies to parse the individual sub-classes of macrophages that are recruited to the mammary ducts and determine whether their phenotype may become more pro-tumor, or "M2", with time.

MUC1 expression is a topic of great interest in a variety of cancer types, and particularly in breast. It is overexpressed in $90 \%$ of human breast cancers, and the secreted form can be detected in the serum of many patients, even those with non-metastatic disease [44]. Thus, it is actively being pursued as a serum bio-marker for early detection. In a previous study, overexpression of the MUC1 cytoplasmic domain in mouse mammary tissue resulted in hyper-branched, hyperplastic ducts with an increased number of terminal end buds [45]. Activation of NF- $\mathrm{kB}$ is one downstream effect of MUC1 signaling, and may have been contributing to the hyperplastic phenotype of that model. In addition, it has been suggested that MUC1 and p65 participate in an auto-inductive loop, as each has been shown to increase expression and/or signaling of the other [33]. Once MUC1 becomes overexpressed and repositioned along the entire cell membrane, it can activate a number of receptor tyrosine kinases, most notably epidermal growth factor receptor (EGFR) [46]. It can also bind to beta-catenin and play a role in activating its downstream target gene targets [45]. Whether MUC1 signaling plays a critical role in the IKMV phenotype remains to be determined. Inhibitors of MUC1 are being developed, which could be combined with our model in future studies to answer this intriguing question [47, 48].

Upon pathological review, we found that the IKMV lesions meet the criteria for the diagnosis of low-grade DCIS [49]. The rate of diagnosis of DCIS in American women has increased due to mammography, and it is currently being debated how aggressively these lesions should be treated. Some argue for minimal treatment, citing that DCIS has been found at autopsy, and thus may never 
progress to a life-threatening condition in a subset of women [50]. However, one retrospective study estimated that $28 \%$ of women treated with biopsy-only for DCIS will develop invasive carcinoma in a follow-up period of approximately 15 years, suggesting that more aggressive treatment is warranted [51]. In the absence of definitive markers of whether the disease will progress beyond DCIS, the frequently suggested treatment is mastectomy or lumpectomy followed by radiation therapy. This strategy appears highly effective with an extremely high percentage of such patients surviving ten years later. However, these women have then undergone the same aggressive treatment as would be proposed for invasive disease. It remains unclear what additional factors may lead the contained lesions into becoming invasive and metastatic as opposed to remaining as DCIS. This is a critical area for research, and future studies using the IKMV model could yield important insights into what physiological and environmental factors combine with inflammatory signaling to promote malignancy in the breast.

\section{Conclusion}

Our model underscores the previously unappreciated effects of short term, aberrant activation of NF- $\mathrm{kB}$ signaling in developmentally normal mammary epithelium. While prolonged inflammatory signaling is recognized as a risk factor for tumorigenesis, we now show that even a short pulse of NF-kB hyper-activation can lead to pre-malignant changes in the breast. Similar changes in architecture and molecular signaling could be occurring in human breast tissue after acute infection, injury, or stress. Thus, inhibition of NF- $\mathrm{KB}$ signaling following acute inflammation or the initial signs of hyperplastic growth could represent an important opportunity for breast cancer prevention.

\section{Additional file}

\section{Additional file 1: Gating strategy for FLOW cytometry data in}

Fig. 7b. An average of 100,000 events were counted for each sample. To start, all samples were taken through the first three gates (top, labeled 1, 2, 3), which excluded artifacts that were not single-cells based on forward and side scatter. From there, DAPI stain was used to determine viability (gate 4). All DAPI negative cells were carried to gate 5 , where cells were split into CD45 positive and CD45 negative populations. The CD45 positive population was then gated using F4/80 on the $x$ axis and CD45 on the $y$ axis (gate 6). Circles indicate CD45 + F4/80+ cells. Values for the graph in Fig. $7 \mathrm{~b}$ were obtained by taking the total number of $\mathrm{CD} 45^{+} \mathrm{F} 4 / 80^{+}$cells counted for each sample and dividing that value by the total number of viable cells counted in the sample (DAPI negative). (PDF $309 \mathrm{~kb}$ )

\section{Abbreviations}

AEBP1: Adipocyte Enhancer-Binding Protein 1; CCL2: Chemokine (C-C motif) ligand 2; MCP-1: Monocyte chemotactic protein 1; CHIP: Chromatin immunoprecipitation; CIKK $\beta$ : Constitutive inhibitor of kappa B kinase beta; CK5: Cytokeratin 5; CK8/18: Cytokeratin 8/18; Cox-2: Cyclooxygenase 2; Csn2: beta casein 2; DCIS: Ductal carcinoma in situ; dox: doxycycline; EGFR: Epidermal growth factor receptor; EMT: Epithelial to mesenchymal transition; ERa: Estrogen receptor alpha; FGFR-1: Fibroblast growth factor receptor 1; IKKß: Inhibitor of kappa B kinase beta; IKMV: double transgenic mouse model used in these studies which allows activation of nuclear factor kappa B signaling specifically in mammary epithelium upon addition of doxycycline to mouse drinking water; IL-1 B: Interleukin 1 beta; IKBa: Inhibitor of kappa B alpha; KO: Knock out; MMTV-rtTA: Mouse mammary tumor virus reverse tetracycline transactivator; MUC1: Mucin 1; NF-kB: Nuclear factor kappa B; PCNA: Proliferating cell nuclear antigen; qRT-PCR: quantitative reverse transcription polymerase chain reaction; RANK: Receptor Activator of NF-kB Kinase; SMA: Smooth muscle actin; TEB: Terminal end bud.

\section{Competing interests}

The authors declare that they have no competing interests.

\section{Authors' contributions}

WB managed the transgenic mouse colony, bred the necessary experimental mice, quantified ductal phenotypes, completed molecular studies including qRT-PCR, ELISA, and flow cytometry and a portion of the immunohistochemistry, and drafted the manuscript. LC assisted in management of the transgenic mouse breeding colony, genotyping of experimental animals, and performing mammary transplant surgeries. OT completed immunohistochemical staining and imaging using confocal microscopy. HO was the first to observe the "filled duct" phenotype and participated in the initial characterization. LG carried out mammary tissue processing, sectioning, and H\&E staining. TPS reviewed histological sections to assess lesions for DCIS criteria and critically revised the relevant manuscript sections. TB was involved in the creation of the transgenic model and critically revised the manuscript. FY conceived of the study, participated in its design and coordination, and helped to draft the manuscript. All authors read and approved the final manuscript.

Authors' information

Not applicable

Availability of data and materials

Not applicable

\section{Acknowledgements}

The work performed in this study was funded by NIH CA113734 awarded to FY, and by a generous donation from Mr. Chris Hill through the Anglo-American Charity, Ltd. All flow cytometry experiments were performed in the VUMC Flow Cytometry Shared Resource supported by the Vanderbilt Ingram Cancer Center (P30 CA68485) and the Vanderbilt Digestive Disease Research Center (DK058404). The authors would also like to thank Allyson Mcleod Perry, Vanderbilt Department of Cancer Biology, for providing reagents and assistance with the PCNA staining protocol, and Dr. Josianne Eid, Dr. Linda Connelly, and Dr. Ryan Ortega for their critical review of the manuscript.

\section{Author details}

'Department of Cancer Biology, Vanderbilt University Medical Center, 23rd Ave S and Pierce PRB 325, Nashville, TN 37232, USA. ${ }^{2}$ Department of Medicine, Division of Allergy, Pulmonary and Critical Care Medicine, Vanderbilt University Medical Center, 1161 21st Ave, Nashville, TN 37232, USA. ${ }^{3}$ Department of Pathology, Vanderbilt University Medical Center, 1161 21st Ave, Nashville, TN 37232, USA. ${ }^{4}$ Vanderbilt-Ingram Cancer Center, 691 Preston Building, 2220 Pierce Ave, Nashville, TN 37232, USA.

Received: 11 February 2015 Accepted: 15 September 2015

Published online: 30 September 2015

\section{References}

1. Hanahan D, Weinberg RA. Hallmarks of cancer: the next generation. Cell. 2011;144:646-74.

2. Hinck L, Näthke I. Changes in cell and tissue organization in cancer of the breast and colon. Curr Opin Cell Biol. 2014;26:87-95.

3. Ernster V, Barclay J, Kerlikowske K, Grady D, Henderson C. Incidence of and Treatment for Ductal Carcinoma In Situ of the Breast. JAMA. 1996;275:913-8.

4. American Cancer Society: Breast Cancer Facts and Figures 2011-2012. American Cancer Society Inc. Atlanta, GA; 2012

5. Wells CJ, O'Donoghue C, Ojeda-Fournier H, Retallack HEG, Esserman $L$ J. Evolving paradigm for imaging, diagnosis, and management of DCIS. J Am Coll Radiol. 2013;10:918-23. 
6. Erbas B, Provenzano E, Armes J, Gertig D. The natural history of ductal carcinoma in situ of the breast: a review. Breast Cancer Res Treat. 2006;97:135-44.

7. Coussens LM, Werb Z. Inflammation and cancer. Nature. 2002;420:860-7.

8. Baeuerle P, Baltimore D. I kappa B: a specific inhibitor of the NF-kappa B transcription factor. Science (80-). 1988;242:540-6.

9. Hayden MS, Ghosh S. Shared principles in NF-kappaB signaling. Cell. 2008;132:344-62

10. Vallabhapurapu S, Karin M. Regulation and function of NF-kappaB transcription factors in the immune system. Annu Rev Immunol. 2009;27:693-733.

11. Zheng C, Yin Q, Wu H. Structural studies of NF-kB signaling. Cell Res. 2011;21:183-95.

12. Connelly L, Barham W, Pigg R, Saint-Jean L, Sherrill T, Cheng D-S, et al. Activation of nuclear factor kappa B in mammary epithelium promotes milk loss during mammary development and infection. J Cell Physiol. 2010;222:73-81.

13. Howe LR, Subbaramaiah K, Hudis CA, Dannenberg AJ. Molecular pathways: adipose inflammation as a mediator of obesity-associated cancer. Clin Cancer Res. 2013;19:6074-83

14. McGregor BA, Antoni MH. Psychological intervention and health outcomes among women treated for breast cancer: a review of stress pathways and biological mediators. Brain Behav Immun. 2009;23:159-66.

15. Brantley DM, Chen CL, Muraoka RS, Bushdid PB, Bradberry JL, Kittrell F, et al. Nuclear factor-kappaB (NF-kappaB) regulates proliferation and branching in mouse mammary epithelium. Mol Biol Cell. 2001;12:1445-55.

16. Connelly L, Barham W, Onishko HM, Sherrill T, Chodosh LA, Blackwell TS, et al. Inhibition of NF-kappa B activity in mammary epithelium increases tumor latency and decreases tumor burden. Oncogene. 2011;30:1402-12.

17. Pratt M, Tibbo E, Robertson SJ, Jansson D, Hurst K, Perez-Iratxeta C, et al. The canonical NF-kappaB pathway is required for formation of luminal mammary neoplasias and is activated in the mammary progenitor population. Oncogene. 2009;28:2710-22.

18. Liu M, Sakamaki T, Casimiro MC, Willmarth NE, Quong AA, Ju X, et al. The canonical NF-kappaB pathway governs mammary tumorigenesis in transgenic mice and tumor stem cell expansion. Cancer Res. 2010;70:10464-73.

19. Gonzalez-Suarez E, Jacob AP, Jones J, Miller R, Roudier-Meyer MP, Erwert R, et al. RANK ligand mediates progestin-induced mammary epithelial proliferation and carcinogenesis. Nature. 2010;468:103-7.

20. Cheng DS, Han W, Chen SM, Sherrill TP, Chont M, Park G-Y, et al. Airway Epithelium Controls Lung Inflammation and Injury through the NF-kappaB Pathway. J Immunol. 2007;178:6504-13.

21. Gunther E, Belka G, Wertheim G, Wang J, Hartman J, Boxer R, et al. A novel doxycycline-inducible system for the transgenic analysis of mammary gland biology. FASEB J. 2002;16:283-92.

22. Connelly L, Robinson-Benion C, Chont M, Saint-Jean L, Li H, Polosukhin W, et al. A transgenic model reveals important roles for the NF-kappa $B$ alternative pathway (p100/p52) in mammary development and links to tumorigenesis. J Biol Chem. 2007;282:10028-35.

23. Dunphy KA, Tao L, Jerry DJ: Mammary epithelial transplant procedure. J Vis Exp 2010, doi: 10.3791/1849

24. Livak KJ, Schmittgen TD. Analysis of relative gene expression data using real-time quantitative PCR and the 2(-Delta Delta C(T)) Method. Methods. 2001;25:402-8

25. Chen C-L, Singh N, Yull FE, Strayhorn D, Van Kaer L, Kerr LD. Lymphocytes Lacking I kappaB-alpha Develop Normally, But Have Selective Defects in Proliferation and Function. J Immunol. 2000;165:5418-27.

26. Reginato MJ, Muthuswamy SK. Illuminating the center: mechanisms regulating lumen formation and maintenance in mammary morphogenesis. J Mammary Gland Biol Neoplasia. 2006;11:205-11.

27. Kawamoto H, Koizumi H, Uchikoshi T. Expression of the G2-M Checkpoint Regulators Cyclin B1 and cdc2 in Nonmalignant and Malignant Human Breast Lesions. Am J Pathol. 1997;150:15-23.

28. Pei X, Bai F, Smith M, Usary J, Fan C, Pai S, et al. CDK Inhibitor p18 INK4C Is a Downstream Target of GATA3 and Restrains Mammary Luminal Progenitor Cell Proliferation and Tumorigenesis. Cancer Cell. 2009;15:389-401.

29. Reed JR, Leon RP, Hall MK, Schwertfeger KL. Interleukin-1 beta and fibroblast growth factor receptor 1 cooperate to induce cyclooxygenase-2 during early mammary tumourigenesis. Breast Cancer Res. 2009;11:R21.

30. Montesano R, Soulié P, Eble JA, Carrozzino F. Tumour necrosis factor alpha confers an invasive, transformed phenotype on mammary epithelial cells. J Cell Sci. 2005;118(Pt 15):3487-500
31. Liu CH, Chang SH, Narko K, Trifan OC, Wu MT, Smith E, et al. Overexpression of cyclooxygenase-2 is sufficient to induce tumorigenesis in transgenic mice. J Biol Chem. 2001;276:18563-9.

32. Choi YS, Chakrabarti R, Escamilla-Hernandez R, Sinha S. Elf5 conditional knockout mice reveal its role as a master regulator in mammary alveolar development: failure of Stat 5 activation and functional differentiation in the absence of Elf5. Dev Biol. 2009;329:227-41.

33. Kufe DW. MUC1-C oncoprotein as a target in breast cancer: activation of signaling pathways and therapeutic approaches. Oncogene. 2013;32:1073-81.

34. Mommers EC, Leonhart AM, von Mensdorff-Pouilly S, Schol DJ, Hilgers J, Meijer CJ, et al. Aberrant expression of MUC1 mucin in ductal hyperplasia and ductal carcinoma In situ of the breast. Int J Cancer. 1999;84:466-9.

35. Lu P, Weaver VM, Werb Z. The extracellular matrix: a dynamic niche in cancer progression. J Cell Biol. 2012;196:395-406.

36. Holloway RW, Bogachev O, Bharadwaj AG, McCluskey GD, Majdalawieh AF, Zhang $L$, et al. Stromal adipocyte enhancer-binding protein (AEBP1) promotes mammary epithelial cell hyperplasia via proinflammatory and hedgehog signaling. J Biol Chem. 2012;287:39171-81.

37. Welm BE, Freeman KW, Chen M, Contreras A, Spencer DM, Rosen JM. Inducible dimerization of FGFR1: development of a mouse model to analyze progressive transformation of the mammary gland. J Cell Biol. 2002;157:703-14

38. Witzel I-I, Koh LF, Perkins ND. Regulation of cyclin D1 gene expression Biochem Soc Trans. 2010;38(Pt 1):217-22.

39. Antonaki A, Demetriades C, Polyzos A, Banos A, Vatsellas G, Lavigne MD, et al. Genomic analysis reveals a novel nuclear factor-kB (NF-kB)-binding site in Alu-repetitive elements. J Biol Chem. 2011;286:38768-82.

40. Pellegrini P, Pasquale P, Cordero A, Alex C, Gallego MI, Marta Ines G, et al. Constitutive activation of RANK disrupts mammary cell fate leading to tumorigenesis. Stem Cells. 2013;31:1954-65.

41. Chua HL, Bhat-Nakshatri P, Clare SE, Morimiya A, Badve S, Nakshatri H. NF-kappaB represses E-cadherin expression and enhances epithelial to mesenchymal transition of mammary epithelial cells: potential involvement of ZEB-1 and ZEB-2. Oncogene. 2007;26:711-24.

42. Ueno T, Toi M, Saji H. Significance of Macrophage Chemoattractant Protein1 in Macrophage Recruitment, Angiogenesis, and Survival in Human Breast Cancer. Clin Cancer Res. 2000;6:3282-9.

43. Valković T, Lucin K, Krstulja M, Dobi-Babić R, Jonjić N. Expression of monocyte chemotactic protein-1 in human invasive ductal breast cancer. Pathol Res Pract. 1998;194:335-40.

44. Li H, Chen K, Su F, Song E, Gong C. Preoperative CA 15-3 levels predict the prognosis of nonmetastatic luminal A breast cancer. J Surg Res. 2014;189:48-56.

45. Li Y, Yi H, Yao Y, Liao X, Xie Y, Yang J, et al. The cytoplasmic domain of MUC1 induces hyperplasia in the mammary gland and correlates with nuclear accumulation of $\beta$-catenin. PLoS One. 2011;6:e19102.

46. Bitler BG, Goverdhan A, Schroeder J. MUC1 regulates nuclear localization and function of the epidermal growth factor receptor. J Cell Sci. 2010;123(Pt 10):1716-23

47. Raina D, Ahmad R, Joshi MD, Yin L, Wu Z, Kawano T, et al. Direct targeting of the mucin 1 oncoprotein blocks survival and tumorigenicity of human breast carcinoma cells. Cancer Res. 2009;69:5133-41.

48. Uchida Y, Raina D, Kharbanda S, Kufe D. Inhibition of the MUC1-C oncoprotein is synergistic with cytotoxic agents in the treatment of breast cancer cells. Cancer Biol Ther. 2013;14:127-34.

49. Bane A. Ductal Carcinoma In Situ: What the Pathologist Needs to Know and Why. Int J Breast Cancer. 2013;2013:914053.

50. Welch H, Black W. Using Autopsy Series To Estimate the Disease "Reservoir" for Ductal Carcinoma in Situ of the Breast: How Much More Breast Cancer Can We Find? Ann Intern Med. 1997;127:1023-8.

51. Page D, Dupont W, Rogers $L$, Landenberger $M$. Intraductal carcinoma of the breast: follow-up after biopsy only. Cancer. 1982;49:751-8. 